\title{
Analysis of platelet-derived growth factor receptor A and oligodendrocyte transcription factor 2 markers following Hydroxychloroquine administration in animal induced multiple sclerosis model
}

\section{Hajar Amin Safaei}

Isfahan University of Medical Sciences

Seyed Mehdi Eftekhari

Isfahan University of Medical Sciences

Mehdi Aliomrani ( $\triangle$ maliomrani@pharm.mui.ac.ir)

Isfahan University of Medical Sciences https://orcid.org/0000-0003-3416-2596

\section{Research Article}

Keywords: Cuprizone, Hydroxychloroquine, PDGFR- a, Olig-2, OPC, Myelin, immunohistochemistry

Posted Date: March 31st, 2021

DOl: https://doi.org/10.21203/rs.3.rs-259276/v1

License: (c) (i) This work is licensed under a Creative Commons Attribution 4.0 International License. Read Full License

Version of Record: A version of this preprint was published at Metabolic Brain Disease on August 3rd, 2021. See the published version at https://doi.org/10.1007/s11011-021-00802-8. 


\section{Abstract}

Background: It has been shown that following demyelination, Oligodendrocyte Progenitor Cells (OPCs) migrate to the lesion site and begin to proliferate, and differentiate. This study aimed to investigate the effects of Hydroxychloroquine (HCQ) on the expression of OLIG-2 and PDGFR-a markers during the myelination process.

Method and Materials: C57BL/ 6 mice were fed cuprizone pellets for 5 weeks to induce demyelination and return to a normal diet for 1 week to stimulate remyelination. During the Phase I all of the animals except CPZ and Vehicle groups were exposed to HCQ $(2.5,10$, and $100 \mathrm{mg} / \mathrm{kg})$ via drinking water. At the end of the study, animals were euthanized, perfused and the brain samples were assessed for myelination and immunohistochemistry evaluation.

Results: What is remarkable is the high rate of Olig2+ cells in the groups treated with 10 and $100 \mathrm{mg} / \mathrm{kg}$ $\mathrm{HCQ}$ in the demyelination phase and its decreasing trend in the remyelination phase. However, there was no significant difference between groups during phase I and Phase II based on the percentage of olig-2+ / total cells in the corpus callosum region. The number of PDGFR- $a+$ cells in the group treated with 10 $\mathrm{mg} / \mathrm{kg} \mathrm{HCQ}$ was significant in the first phase (pvalue<0.05).

Discussion: Considering that the $100 \mathrm{mg} / \mathrm{kg} \mathrm{HCQ}$ group had the highest level of PDGFR-a as well as the highest level of myelin repair in LFB staining, it could be inferred that it was the most effective dose in inducing proliferation and migration of OPCs.

\section{Introduction}

Multiple sclerosis (MS) is an inflammatory autoimmune disease of the central nervous system (CNS) [1], [2]. In this disease, the myelin sheath, which covers the neurons, is damaged by T-cell infiltration, inflammatory attacks on the CNS, and overexpression of proinflammatory mediators. As such, transmission of neural messages will be disrupted [3] given the unknown cause of the disease, there is no definitive treatment for this disease and the current treatments reduce only the duration of the acute period of the disease. Corticosteroids, Interferon beta and Glatiramer acetate are among the first-line treatments for the disease which impose many side effects and costs on the patient[4].

It has been shown that following demyelination, Oligodendrocyte Progenitor Cells (OPCs) accumulate at the lesion site and begin to proliferate, migrate, and differentiate, while forming a multifaceted myelin sheath around the damaged axons[5]. According to recent studies, increasing the activity of these cells will increase myelination and contribute to the treatment of MS. Moreover, the role of microglia, considered as macrophages of the brain and spinal cord, has been proven in increasing the destruction of myelin and nerve cells as well as the creation of MS. Therefore, new methods of treatment tend to develop strategies for reducing the activity of microglia and increasing the activity and differentiation of oligodendrocytes [6], [7]. Platelet-derived growth factor alpha (PDGF-a) has both proliferative and 
migratory properties [8]-[10], and controls the survival, proliferation and migration of OPCs through PDGFR-a, which is only one of its receptor isomers and expressed by OPCs themselves[11], [12].

Oligodendrocyte transcription factor (OLIG2) is one of the most important members of the basic helixloop-helix (bHLH) family, which encodes many transcription factors. The expression of this protein in the central nervous system is mostly in motor neurons and oligodendrocytes. This factor leads to the differentiation and maturation of migrating oligodendrocyte precursors to mature oligodendrocytes and is, therefore, a neurogenic factor. It is worth noting that many OPCs accumulated in the acute or chronic demyelinated site do not differentiate into mature oligodendrocytes. As such, this differentiation is significant and these cells' activity in myelin regeneration is highly important. Therefore, olig-2 is used as a specific factor in the activation of these OPCs and their differentiation is considered a marker for the effectiveness of treatment of demyelination/remyelination induced models such as cuprizone(CPZ)[13], [14].

As an anti-malarial drug with immunomodulatory and anti-inflammatory properties, Hydroxychloroquine (HCQ) is widely used in autoimmune diseases such as lupus and rheumatoid arthritis[15]. This drug crosses the blood-brain barrier and tends to be accumulated in the tissues[16]-[18]. Studies evaluating the efficacy of hydroxychloroquine in the animal model of EAE (induced by antigenic stimulation of the immune system) promise the effect of this drug on reducing the activity of microglia and myelin regeneration through influencing the expression of the level of inflammatory cytokines produced by microglia such as IL-6 and TNF-a [19]. Considering the above mentioned factors and given that the clinical trial related to the use of this drug is underway in MS patients in Canada[20], this study investigated the effect of HCQ on PDGF specific receptor (PDGFR-a) and Olig-2 protein as downstream factors affecting myelination process in an animal model of cuprizone-induced MS.

\section{Materials And Methods}

\section{2-1. ANIMALS}

C57BL/ 6 mice were purchased from RAZI institute (KRAJ, I.R. Iran), weighing 20-25 gr, and housed in center of laboratory of ISFAHAN Pharmacology Department at 12/12h light/dark cycle (temperature 20$25^{\circ} \mathrm{C}$ and relative humidity 50-60\%). Animals were maintained in routine cages (5-6 per cage) and had access to food and water ad libitum. The mice were given one week to adapt their new place. All of the experiments were approved by IRAN National Committee for Ethic in Biomedical research (IR.MUI.RESEARCH.REC 1397.451), and were carried out in accordance with the Guidelines for Car and Use of laboratory Animals.

\section{2-2. Experimental Design}

Animals were randomly divided into five groups: Group 1 (negative control, $n=5$ ) which were fed with normal diet to serve as healthy group and they were sacrificed after five weeks. Group 2 (positive control, $\mathrm{n}=10)$ which received pellets containing $0.2 \%(\mathrm{w} / \mathrm{w})$ cuprizone (Sigma-Aldrich, USA) and normal water for 
five weeks to induce demyelination in the corpus callosum (demyelination phase). Groups 3,4 and 5 (each group, $n=10$ ) received pellets containing $0.2 \%$ cuprizone and water containing $2.5,10$ and $100 \mathrm{mg}$ per kg body weight hydroxychloroquine respectively for five weeks. Half of the animals in groups 2-5 were randomly selected, deeply anesthetized and perfused at the end of fifth week (Phase I). Unsacrificed animals were put on normal diet to induce remyelination for one week, and at the end of seventh day all of them were sacrificed (Phase II).

\section{2-3. Cardiac perfusion}

For immunohistochemical study LFB staining at the end of each phase mice were intracardially perfused with $5 \mathrm{ml}$ phosphate buffered saline (PBS) $1 \mathrm{M}$, followed by $5 \mathrm{ml}$ of $4 \%$ neutral formalin (Merck) to accelerate tissue fixation. Brain tissue was quickly removed from skull and washed with cold PBS, then samples were kept in fixative for 24 hours [21]

\section{2-4. Myelin staining}

Tissue sections were analyzed using luxol fast blue staining (Sigma, USA). Samples were placed in luxol fast blue overnight at $60^{\circ} \mathrm{C}$ and washed with $95 \%$ alcohol followed by distilled water to remove the excess blue stain. The blue color was trapped in myelinated white matter after lithium carbonate exposure step $(20 \mathrm{sec})$. Slides were washed three times with $75 \%$ alcohol and the background was stained with cresyl violet for $1 \mathrm{~min}$. With this technique myelinated fibers (blue), neutrophils (pink) and nerve cells (purple) were visualized with different colors[22]

\section{2-5. Immunohistochemistry}

Coronal incisions of brain tissue were prepared from $8 \mu \mathrm{m}$-thick paraffin sections, dried for $20 \mathrm{~min}$ in an $80{ }^{\circ} \mathrm{C}$ oven. Slides were dewaxed in xylene for $20 \mathrm{~min} 3$ times, and rehydrated in graded alcohol. Tissues were pretreated with Tris-EDTA buffer (TE buffer, $1 \mathrm{M}, \mathrm{pH}$ 9) or citrate buffer (1 M, pH 6) 10 min for antigenic retrieval.

Rabbit monoclonal anti-olig2 (EPR2376) and rat monoclonal to PDGF receptor alpha (APA5) were used as a primary antibodies and staining was performed in accordance with the supplier instructions (Abcam, UK). Briefly, sections were incubated with the primary antibodies Olig-2 (1:10) and PDGFR-a (1:10) for 1h at room temperature. Then washed 3 times with PBS, and blocked with $0.03 \%$ hydrogen peroxide blocking solution for $10 \mathrm{~min}$. After that slides were incubated with the secondary antibody for $10 \mathrm{~min}$ at room temperature. Finally, 3-3'diaminobenzidine (DAB) was used to visualize immunoreactivity of the samples. Also the slides were counter-stained using hematoxylin then dehydrated and mounted for microscopic observation. Target positive cells were counted 3 times in each slides of the tissue samples with Fiji software.

\section{2-6 Statistical Analyses}


All statistical analyses were performed using Graph Pad Prism 8.Ink. Data are shown as the mean \pm standard deviation. All of the statistical differences were assessed using one-way ANOVA following Tukeys post-hoc test and $\mathrm{P}<0.05$ were considered as a statistically significant.

\section{Results}

\section{3-1. Myelin content}

As can be seen in figure 1, the CPZ group shows a clear decrease in the level of myelin in the demyelination phase, while the level of myelin degradation has been decreased in the remyelination phase. No significant difference was observed in both phases between the CPZ group and the group which had received $2.5 \mathrm{mg} / \mathrm{kg} \mathrm{HCQ}$. However, in the first phase, less demyelination was observed in the groups treated with doses of $10 \mathrm{mg} / \mathrm{kg} \mathrm{HCQ}$ and $100 \mathrm{mg} / \mathrm{kg} \mathrm{HCQ}$ than the CPZ group (P value $<0.001$ ). What is remarkable is the significant difference between the group treated with the dose of $100 \mathrm{mg} / \mathrm{kg}$ HCQ and other groups in the second phase $(p$ value $<0.05)$

\section{3-2. Changes in the PDGFR-a marker}

With regard to the PDGFR-a marker, the total number of cells with this marker as well as the percentage of these cells in SVZ (Fig.2A-C) and corpus callosum region (Fig.3A-C) have been shown. Generally, the high rate of cells with this marker in the demyelination phase followed by their decrease in the remyelination phase is remarkable (CPZ group in two phases; $P$ value $=0.0049)$. This decreasing trend is clearly visible in the groups treated with the doses of $10 \mathrm{mg} / \mathrm{kg} \mathrm{HCQ}$ and, especially, $100 \mathrm{mg} / \mathrm{kg} \mathrm{HCQ}$. But, no significant difference was observed between the two phases at the dose of $2.5 \mathrm{mg} / \mathrm{kg} \mathrm{HCQ}$. Interestingly, evaluating the ratio of the cells with this marker to the total number of cells counted in the SVZ did not show any significant differences between the study groups except for CPZ group (pvalue<0.05). Similar trend was observed in the corpus callosum at 40x magnification between the groups (Fig.3-C). However, the number of positive cells for PDGFR-a in the group treated with $10 \mathrm{mg} / \mathrm{kg} \mathrm{HCQ}$ was so significant in the first phase (pvalue<0.05). This difference was even confirmed in the percentage chart of the examined cells.

\section{3-3. Changes in the Olig-2 marker}

With regard to the olig-2 marker, the total number of cells with this marker as well as the percentage of these cells in SVZ (Fig.4A-C) and corpus callosum (Fig.5A-C) have been shown. What is remarkable is the high rate of cells with this marker in the treatment groups of $10 \mathrm{mg} / \mathrm{kg} \mathrm{HCQ}$ and $100 \mathrm{mg} / \mathrm{kg} \mathrm{HCQ}$ in the demyelination phase and its decreasing trend in the remyelination phase. The percentage of cells with olig-2 marker showed a similar trend. Very similar trend was observed in the total number of cells with olig-2 in the corpus callosum region (with a 40x magnification) between the groups (Fig.5-C). Given the percentage of olig-2 cells in this region, no significant difference was observed between remyelination and demyelination phases in the treatment groups.

\section{Discussion}


MS, as the most prevalent cause of neurological disability in young adults[6], [23], is estimated to affect approximately 2.5 million people all around the world. There are a variety of models for investigating the demyelinating and neurodegenerative inflammatory processes of MS which include experimental allergic encephalomyelitis (EAE), demyelination induced by viral infections such as Theiler's virus, demyelination caused by toxic compounds such as cuprizone, injection of ethidium bromide / lysolecithin, and X-rayinduced demyelination[24], [25]. Cuprizone-induced model, because of its high reproducibility, ease of execution/implementation and non-invasive nature, has been shown to be one of the best models for the induction of MS[26], [27]. As expected, like the previous studies, the results of the LFB staining showed that in the first phase, the level of myelin degradation in the CPZ group was strongly severe and the lesion improved somewhat after the discontinuation of the exposure to this toxin in the second phase. This can be probably due to the discontinuation of Cuprizone and increased survival of oligodendrocytes. Among the treated groups, the $2.5 \mathrm{mg} / \mathrm{kg} \mathrm{HCQ}$ group behaved similarly to the CPZ group in both phases, indicating that this dose of the drug was ineffective. In both phases, $100 \mathrm{mg} / \mathrm{kg} \mathrm{HCQ}$ therapeutic doses had the greatest effect in repairing and stopping myelin destruction.

In the central nervous system, neuronal stem cells first differentiate into oligodendrocyte progenitor cells. These cells make up 5 to $8 \%$ of all nerve cells/ neurons and are found in the optic nerves, cerebellum, motor cortex, and corpus callosum, and have a high ability of proliferation and differentiation. These cells differentiate into immature oligodendrocytes. Immature oligodendrocytes, finally, differentiate into myelinating oligodendrocytes and repair myelin [28].

Oligodendrocyte progenitor cells maintain the cells' proliferation and differentiation ability long after birth with severe myelination, and produce new but slower oligodendrocytes throughout life[29]. There are a wide range of markers such as PDGFR-a, NG2, GD3, and MyT1 for the identification of OPCs[30]. Previous studies have shown the expression of PDGFR-a on the surface of parenchymal oligodendrocyte progenitor cells (pOPCs) and its role in remyelination following induced demyelination in animal models. These specific receptors, which are essentially tyrosine kinases, following the binding of PDGF-a, transfer the signals into the cell by phosphorylating themselves and other involved proteins. The result of this transfer is the cellular response including survival, evolution, migration, and differentiation[31]. PDGFR-a is currently the most reliable marker for identifying OPCs[2]. The observed results are in line with the previous studies as the level of PDGFR-a increased in the CPZ group than the control group [32], [33]. According to the studies, PDGFR-a gives a strong proliferative response to demyelination [34]-[36].

In the SVZ, the increase of drug dose led to the increase of the PDGFR-a marker in the first phase and the overall decrease of the number of markers in the second phase. Since in the developed central nervous system, PDGFR-a is specifically expressed in immature OPCs, and its expression is silenced when OPCs enter the differentiation stage[37], [38], it can be said that the dose-dependent drug has been effective in the proliferation and migration of OPCs.

The general decrease in the second phase seems to be due to the fact that in this phase, the proliferating and migrating cells of the first phase have entered the differentiation stage and the discontinuation of 
CPZ has caused the survival of mature oligodendrocytes more than the first phase; because studies have shown that cuprizone is toxic to oligodendrocytes but not toxic to oligodendrocyte progenitor cells[39]. Among the treatment groups, the group treated with $100 \mathrm{mg} / \mathrm{kg} \mathrm{HCQ}$ dose had the highest rate and the lowest percent in the first phase and the highest rate and percent in the second phase, indicating the better effectiveness of this dose.

The decrease of this marker in the corpus callosum region compared to SVZ is probably due to the migration of OPCs expressing PDGFR- $a$ towards the corpus callosum and settlement in this region. The reason is that after receiving Cuprizone, mature oligodendrocytes become apoptosis. In the ventricular region, progenitor cells begin to proliferate and migrate to demyelinated regions in the corpus callosum and cortex, and are transferred to mature oligodendrocytes[40]. The increase of PDGFR-a in both phases in the $10 \mathrm{mg} / \mathrm{kg} \mathrm{HCQ}$ group, compared to the $100 \mathrm{mg} / \mathrm{kg} \mathrm{HCQ}$ group, is probably due to the fact that the latter is associated with more proliferation, accelerated migration and premature puberty than the former. LFB staining confirms this claim. Increase in the percent of the $10 \mathrm{mg} / \mathrm{kg}$ HCQ group had probably been due to an increase in immature cells, while decrease in the percent of the $100 \mathrm{mg} / \mathrm{kg} \mathrm{HCQ}$ group had been due to an increase in mature cells. It can be said that the decreased percent in the second phase in the groups had been due to the increase of mature cells.

Of the bHLH family, two transcription factors of olig-1 and olig-2 play an important role in both processes of myelogenesis and myelin repair[41]. Many studies have shown that the transcription factor of olig-2 converts neuronal precursors to oligodendrocyte precursors and increases its expression in acute and chronic demyelinating lesions. This overexpression in turn causes the production of differentiated oligodendrocytes and premature mylenisation[42], [43]. Olig-2 is an oligodendrocyte lineage marker expressed in all stages of this cell line[13], [14]. The expression of this marker is high in OPCs so that olig$2^{\text {+strong }}$ cells are identified as progenitor cells. It has, however, a lower expression in oligodendrocytes so that olig-2 ${ }^{\text {tweakly }}$ cells are identified as mature oligodendrocytes[44]. In animal studies of the cuprizone model, the accumulation of OPCs and oligodendrocytes begins after discontinuation of cuprizone, and OPCs differentiate into mature oligodendrocytes, with the olig-2 transcription factor and its downstream protein, zinc finger protein, playing a key role in this stage[13], [14]. As such, the presence of olig-2 generally means that the progenitor cells belong to the oligodendrocyte class and do not differentiate into astrocytes or neurons.

The results of our study are fortunately consistent with previous studies[45], as the number of cells with olig-2 marker in the SVZ and the corpus callosum region in the CPZ group was higher than in the control group. In the evaluation of total cell in SVZ and in the first phase, it was shown that in the groups receiving the drug, the level of olig-2 in the $2.5 \mathrm{mg} / \mathrm{kg} \mathrm{HCQ}$ dose was slightly higher than the group of $\mathrm{CPZ}$, and in LFB staining, this group behaved similar to the group of CPZ. Therefore, it can be argued that this dose of the drug has not been successful in differentiating precursors into oligodendrocytes. In the same phase, the level of olig-2 in $10 \mathrm{mg} / \mathrm{kg} \mathrm{HCQ}$ group was higher than the $100 \mathrm{mg} / \mathrm{kg} \mathrm{HCQ}$ group. This dose of the drug appears to induce differentiation of many neuronal precursors into OPC. However, given the fact that in LFB staining the $100 \mathrm{mg} / \mathrm{kg} \mathrm{HCQ}$ showed a better performance, it seems that $100 \mathrm{mg} / \mathrm{kg} \mathrm{HCQ}$ 
dose has led to premature differentiation of OPCs as well as premature maturation of oligodendrocytes. Studies have shown that overexpression of olig2 increases the rate of remylation and induces differentiation of OPCs in demyelinated lesions[46]. The overall decrease in the second phase, compared to the first phase, probably means that a high number of differentiated OPCs have transferred to mature oligodendrocytes. In this phase, in the groups receiving the drug, the increase of dose led to a decrease of olig2. Thus, it can be said that the increase of the drug's dose led to more differentiation and maturity. The highest rate belonged to the $2.5 \mathrm{mg} / \mathrm{kg} \mathrm{HCQ}$ group that behaved similar to the CPZ group. This behavior suggests that the OPCs remained immature[47], which was consistent with the LFB results. The lowest level belonged to the $100 \mathrm{mg} / \mathrm{kg} \mathrm{HCQ}$ group, indicating the better performance of this dose in the maturation of oligodendrocyte. This result was also in line with the LFB results. With regard to the percent of olig-2 calculated in SVZ, we at first glance encounter an increase in the percentage of total cells. In percentage, the cells which had turned blue in IHC staining and did not actually have the olig-2 marker had been included in the calculations. Therefore, the increased percent in the first phase means the decrease of the blue cells which do not belong to the oligodendrocyte class. As such, the increase of the percent means the increase of the differentiation induction. In both phases, the $100 \mathrm{mg} / \mathrm{kg} \mathrm{HCQ}$ group had the highest percentage. This dose seems to have been successful in early differentiation which is confirmed by LFB staining. An overall decrease of percentage was observed in the second phase compared to the first phase. Given the decrease of olig- 2 in the second phase, which is actually indicative of the conversion of differentiated cells into mature oligodendrocytes, it seems that this decrease of percentage in the second phase was due to the decrease of olig-2. Interestingly, the same behavioral patterns were observed in the corpus callosum.

\section{Conclusion}

Considering that the $100 \mathrm{mg} / \mathrm{kg} \mathrm{HCQ}$ group had the highest level of PDGFR-a as well as the highest level of myelin repair in LFB staining, it could be inferred that it was the most effective dose in inducing proliferation and migration of OPCs in this study. Moreover, the evaluation of the level and percent of olig2 at this dose shows the effectiveness of this dose in inducing the differentiation and maturation of oligodendrocytes. Therefore, it seems that the use of hydroxychloroquine with the dose of $100 \mathrm{mg} / \mathrm{kg}$ HCQ can be effective in the treatment of MS.

\section{Declarations}

\section{Funding:}

This study was supported by a grant (Project No. 397640) from Isfahan Pharmaceutical Science Research Center, Isfahan University of Medical Sciences, Isfahan, Iran.

\section{Conflicts of interest/Competing interests:}

All authors declare no conflict of interest. 


\section{Ethics approval:}

All procedures were approved by the Iran National Committee for Ethics in Biomedical Research (IR.MUI.RESEARCH.REC.1397.451) which was performed in accordance with the Guidelines for the Care and Use of Laboratory Animals.

\section{Author's contribution:}

HAS and MAO conceived of the presented idea, HAS and SME carried out the experiment, SME and MAO helped supervise the project, all authors provided critical feedback and helped shape the research, analysis and manuscript.

\section{References}

[1] L. Belbasis, V. Bellou, E. Evangelou, J. P. A. loannidis, and I. Tzoulaki, "Environmental risk factors and multiple sclerosis: an umbrella review of systematic reviews and meta-analyses," Lancet Neurol., vol. 14, no. 3, pp. 263-273, Mar. 2015, doi: 10.1016/S1474-4422(14)70267-4.

[2] Y. Tian, H. Yin, X. Deng, B. Tang, X. Ren, and T. Jiang, "CXCL12 induces migration of oligodendrocyte precursor cells through the CXCR4-activated MEK/ERK and PI3K/AKT pathways," Mol. Med. Rep., vol. 18, no. 5, pp. 4374-4380, 2018.

[3] C. S. Frohman, E.M.; Racke, M.K.; Raine, "No TitleMultiple sclerosis-The plaque and its pathogenesis.," N. Engl. J. Med., pp. 942-955, 2006.

[4] M. M. Goldenberg, "Multiple sclerosis review," Pharm. Ther., vol. 37, no. 3, p. 175, 2012.

[5] R. J. M. Franklin and C. Ffrench-Constant, "Remyelination in the CNS: from biology to therapy," Nat. Rev. Neurosci., vol. 9, no. 11, pp. 839-855, Nov. 2008, doi: 10.1038/nrn2480.

[6] M. Aliomrani, M. A. Sahraian, H. Shirkhanloo, M. Sharifzadeh, M. R. Khoshayand, and M. H.

Ghahremani, "Blood concentrations of cadmium and lead in multiple sclerosis patients from Iran," Iran. J. Pharm. Res. IJPR, vol. 15, no. 4, p. 825, 2016.

[7] B. Paknejad, H. Shirkhanloo, and M. Aliomrani, "Is There Any Relevance Between Serum Heavy Metal Concentration and BBB Leakage in Multiple Sclerosis Patients?," Biol. Trace Elem. Res., vol. 190, no. 2, pp. 289-294, 2019.

[8] C. ffrench-C. Emmanuel Garcion, Andreas Faissner, "No TitleKnockout mice reveal a contribution of the extracellular matrix molecule tenascin-C to neural precursor proliferation and migration," Development, vol. 128, no. 13, pp. 2485-2496, 2001.

[9] C. ffrench-C. K.L. Blaschuk, E.E. Frost, "No TitleThe regulation of proliferation and differentiation in oligodendrocyte progenitor cells by alphaV integrins," Development, vol. 127, no. 9, pp. 1961-1969, 2000. 
[10] B. W. Kiernan, B. Götz, A. Faissner, and C. Ffrench-Constant, "Tenascin-C Inhibits Oligodendrocyte Precursor Cell Migration by both Adhesion-Dependent and Adhesion-Independent Mechanisms," Mol. Cell. Neurosci., vol. 7, no. 4, pp. 322-335, Apr. 1996, doi: 10.1006/mcne.1996.0024.

[11] R. D. McKinnon, T. Matsui, M. Dubois-Dalcq, and S. A. Aaronsont, "FGF modulates the PDGF-driven pathway of oligodendrocyte development," Neuron, vol. 5, no. 5, pp. 603-614, Nov. 1990, doi:

10.1016/0896-6273(90)90215-2.

[12] N. Pringle, E. J. Collarini, M. J. Mosley, C. H. Heldin, B. Westermark, and W. D. Richardson, “PDGF A chain homodimers drive proliferation of bipotential (O-2A) glial progenitor cells in the developing rat optic nerve.," EMBO J., vol. 8, no. 4, pp. 1049-1056, Apr. 1989, doi: 10.1002/j.1460-2075.1989.tb03472.x.

[13] J. Praet, C. Guglielmetti, Z. Berneman, A. Van der Linden, and P. Ponsaerts, "Cellular and molecular neuropathology of the cuprizone mouse model: Clinical relevance for multiple sclerosis," Neurosci. Biobehav. Rev., vol. 47, pp. 485-505, Nov. 2014, doi: 10.1016/j.neubiorev.2014.10.004.

[14] A. Othman, D. M. Frim, P. Polak, S. Vujicic, B. G. W. Arnason, and A. I. Boullerne, "Olig1 is expressed in human oligodendrocytes during maturation and regeneration," Glia, vol. 59, no. 6, pp. 914-926, Jun. 2011, doi: 10.1002/glia.21163.

[15] F. Mazloumfard, M. Mirian, S.-M. Eftekhari, and M. Aliomrani, "Hydroxychloroquine effects on miR155-3p and miR-219 expression changes in animal model of multiple sclerosis," Metab. Brain Dis., pp. 1$9,2020$.

[16] L. Gustafsson, B. Lindstrom, A. Grahnen, and G. Alvan, "Chloroquine excretion following malaria prophylaxis.," Br. J. Clin. Pharmacol., vol. 24, no. 2, pp. 221-224, Aug. 1987, doi: 10.1111/j.13652125.1987.tb03165.x.

[17] A. H. Mackenzie, "Dose refinements in long-term therapy of rheumatoid arthritis with antimalarials," Am. J. Med., vol. 75, no. 1, pp. 40-45, Jul. 1983, doi: 10.1016/0002-9343(83)91269-X.

[18] D. Plantone and T. Koudriavtseva, "Current and Future Use of Chloroquine and Hydroxychloroquine in Infectious, Immune, Neoplastic, and Neurological Diseases: A Mini-Review," Clin. Drug Investig., vol. 38, no. 8, pp. 653-671, Aug. 2018, doi: 10.1007/s40261-018-0656-y.

[19] M. W. Koch et al., "Hydroxychloroquine reduces microglial activity and attenuates experimental autoimmune encephalomyelitis," J. Neurol. Sci., vol. 358, no. 1-2, pp. 131-137, 2015.

[20] S. Faissner et al., "Unexpected additive effects of minocycline and hydroxychloroquine in models of multiple sclerosis: Prospective combination treatment for progressive disease?," Mult. Scler. J., vol. 24, no. 12, pp. 1543-1556, 2018.

[21] G. J. Gage, D. R. Kipke, and W. Shain, "Whole Animal Perfusion Fixation for Rodents," J. Vis. Exp., no. 65 , Jul. 2012, doi: $10.3791 / 3564$. 
[22] C. Laule et al., "Myelin water imaging in multiple sclerosis: quantitative correlations with histopathology," Mult. Scler. J., vol. 12, no. 6, pp. 747-753, Nov. 2006, doi: 10.1177/1352458506070928.

[23] M. Aliomrani, M. A. Sahraian, H. Shirkhanloo, M. Sharifzadeh, M. R. Khoshayand, and M. H. Ghahremani, "Correlation between heavy metal exposure and GSTM1 polymorphism in Iranian multiple sclerosis patients," Neurol. Sci., vol. 38, no. 7, pp. 1271-1278, 2017.

[24] C. Procaccini, V. De Rosa, V. Pucino, L. Formisano, and G. Matarese, "Animal models of Multiple Sclerosis," Eur. J. Pharmacol., vol. 759, pp. 182-191, Jul. 2015, doi: 10.1016/j.ejphar.2015.03.042.

[25] H. G. Kuhn, T. D. Palmer, and E. Fuchs, "Adult neurogenesis: a compensatory mechanism for neuronal damage," Eur. Arch. Psychiatry Clin. Neurosci., vol. 251, no. 4, pp. 152-158, Aug. 2001, doi: $10.1007 / \mathrm{s} 004060170035$.

[26] W. F. Blakemore and R. J. M. Franklin, "Remyelination in Experimental Models of Toxin-Induced Demyelination," 2008, pp. 193-212.

[27] R. H. Miller, S. Fyffe-Maricich, and A. C. Caprariello, "Animal Models for the Study of Multiple Sclerosis," in Animal Models for the Study of Human Disease, Elsevier, 2017, pp. 967-988.

[28] R. J. M. Franklin and S. A. Goldman, "Glia Disease and Repair-Remyelination," Cold Spring Harb. Perspect. Biol., vol. 7, no. 7, p. a020594, Jul. 2015, doi: 10.1101/cshperspect.a020594.

[29] B. Emery, "Regulation of oligodendrocyte differentiation and myelination," Science (80-. )., vol. 330, no. 6005 , pp. 779-782, 2010.

[30] M. Jana and K. Pahan, "Astrocytes, Oligodendrocytes and Schwann Cells," in Neuroimmune Pharmacology, Springer, 2017, pp. 117-140.

[31] M. Zawadzka et al., "CNS-Resident Glial Progenitor/Stem Cells Produce Schwann Cells as well as Oligodendrocytes during Repair of CNS Demyelination," Cell Stem Cell, vol. 6, no. 6, pp. 578-590, Jun. 2010, doi: 10.1016/j.stem.2010.04.002.

[32] E. Zeldich, C.-D. Chen, R. Avila, S. Medicetty, and C. R. Abraham, "The Anti-Aging Protein Klotho Enhances Remyelination Following Cuprizone-Induced Demyelination," J. Mol. Neurosci., vol. 57, no. 2, pp. 185-196, Oct. 2015, doi: 10.1007/s12031-015-0598-2.

[33] E. G. Baxi et al., "Lineage tracing reveals dynamic changes in oligodendrocyte precursor cells following cuprizone-induced demyelination," Glia, vol. 65, no. 12, pp. 2087-2098, Dec. 2017, doi: 10.1002/glia.23229.

[34] F. J. Sim, C. Zhao, J. Penderis, and R. J. M. Franklin, "The Age-Related Decrease in CNS Remyelination Efficiency Is Attributable to an Impairment of Both Oligodendrocyte Progenitor Recruitment 
and Differentiation," J. Neurosci., vol. 22, no. 7, pp. 2451-2459, Apr. 2002, doi: 10.1523/JNEUROSCI.2207-02451.2002.

[35] R. H. Woodruff, M. Fruttiger, W. D. Richardson, and R. J. . Franklin, "Platelet-derived growth factor regulates oligodendrocyte progenitor numbers in adult CNS and their response following CNS demyelination," Mol. Cell. Neurosci., vol. 25, no. 2, pp. 252-262, Feb. 2004, doi: 10.1016/j.mcn.2003.10.014.

[36] R. C. Armstrong, T. Q. Le, E. E. Frost, R. C. Borke, and A. C. Vana, "Absence of Fibroblast Growth Factor 2 Promotes Oligodendroglial Repopulation of Demyelinated White Matter," J. Neurosci., vol. 22, no. 19, pp. 8574-8585, Oct. 2002, doi: 10.1523/JNEUROSCI.22-19-08574.2002.

[37] Y. Zhu et al., "Control of oligodendrocyte generation and proliferation by Shp2 protein tyrosine phosphatase," Glia, vol. 58, no. 12, pp. 1407-1414, Sep. 2010, doi: 10.1002/glia.21016.

[38] S. L. Fyffe-Maricich, J. C. Karlo, G. E. Landreth, and R. H. Miller, "The ERK2 Mitogen-Activated Protein Kinase Regulates the Timing of Oligodendrocyte Differentiation," J. Neurosci., vol. 31, no. 3, pp. 843-850, Jan. 2011, doi: 10.1523/JNEUROSCI.3239-10.2011.

[39] V. Tsiperson et al., "Brain-Derived Neurotrophic Factor Deficiency Restricts Proliferation of Oligodendrocyte Progenitors Following Cuprizone-Induced Demyelination," ASN Neuro, vol. 7, no. 1, p. 175909141456687, Feb. 2015, doi: 10.1177/1759091414566878.

[40] Y. Zhang et al., "Quetiapine enhances oligodendrocyte regeneration and myelin repair after cuprizone-induced demyelination," Schizophr. Res., vol. 138, no. 1, pp. 8-17, Jun. 2012, doi:

10.1016/j.schres.2012.04.006.

[41] H. A. Arnett, "bHLH Transcription Factor Olig1 Is Required to Repair Demyelinated Lesions in the CNS," Science (80-. )., vol. 306, no. 5704, pp. 2111-2115, Dec. 2004, doi: 10.1126/science.1103709.

[42] E. G. Rodriguez et al., "Oligodendroglia in cortical multiple sclerosis lesions decrease with disease progression, but regenerate after repeated experimental demyelination," Acta Neuropathol., vol. 128, no. 2, pp. 231-246, Aug. 2014, doi: 10.1007/s00401-014-1260-8.

[43] Z. Ou et al., "Olig2-Targeted G-Protein-Coupled Receptor Gpr17 Regulates Oligodendrocyte Survival in Response to Lysolecithin-Induced Demyelination," J. Neurosci., vol. 36, no. 41, pp. 10560-10573, Oct. 2016, doi: 10.1523/JNEUROSCI.0898-16.2016.

[44] T. Kuhlmann, V. Miron, Q. Cuo, C. Wegner, J. Antel, and W. Bruck, "Differentiation block of oligodendroglial progenitor cells as a cause for remyelination failure in chronic multiple sclerosis," Brain, vol. 131, no. 7, pp. 1749-1758, Jul. 2008, doi: 10.1093/brain/awn096.

[45] R. Milo and E. Kahana, "Multiple sclerosis: Geoepidemiology, genetics and the environment," Autoimmun. Rev., vol. 9, no. 5, pp. A387-A394, Mar. 2010, doi: 10.1016/j.autrev.2009.11.010. 
[46] A. Wegener et al., "Gain of Olig2 function in oligodendrocyte progenitors promotes remyelination," Brain, vol. 138, no. 1, pp. 120-135, Jan. 2015, doi: 10.1093/brain/awu375.

[47] Y. Jia et al., "Cordycepin (3'-deoxyadenosine) promotes remyelination via suppression of neuroinflammation in a cuprizone-induced mouse model of demyelination," Int. Immunopharmacol., vol. 75, p. 105777, Oct. 2019, doi: 10.1016/j.intimp.2019.105777.

\section{Table}

Table 1. Changes in the amount of myelin measured by LFB staining in the first phase (demyelination) and the second phase (remelination). Data is reported as Mean \pm SD.

\begin{tabular}{|c|c|c|c|c|c|c|c|c|c|}
\hline \multirow[b]{2}{*}{ Groups } & \multicolumn{4}{|c|}{ PHASE 1} & \multicolumn{4}{|c|}{ PHASE 2} & \multirow[t]{2}{*}{$P$ value } \\
\hline & Mean & SD & $\begin{array}{l}\text { Lower } \\
95 \% \mathrm{Cl}\end{array}$ & $\begin{array}{l}\text { Upper } \\
95 \% \mathrm{Cl}\end{array}$ & Mean & SD & $\begin{array}{l}\text { Lower } \\
95 \% \mathrm{Cl}\end{array}$ & $\begin{array}{l}\text { Upper } \\
95 \% \mathrm{Cl}\end{array}$ & \\
\hline Control & 101.1 & 6.38 & 93.67 & 109.5 & 101.1 & 6.38 & 93.67 & 109.5 & $>0.9$ \\
\hline Cuprizone & 17.0 & 5.14 & 10.61 & 23.39 & 44.4 & 10.92 & 30.84 & 57.76 & 0.0004 \\
\hline $\begin{array}{l}2.5 \mathrm{mg} / \mathrm{kg} \\
\mathrm{HCQ}\end{array}$ & 14.06 & 3.65 & 10.07 & 19.93 & 47.2 & 5.11 & 40.84 & 53.56 & $<0.0001$ \\
\hline $\begin{array}{l}10 \mathrm{mg} / \mathrm{kg} \\
\mathrm{HCQ}\end{array}$ & 56.2 & 10.23 & 43.49 & 68.91 & 52.6 & 6.02 & 45.12 & 60.08 & $>0.9$ \\
\hline $\begin{array}{l}100 \\
\mathrm{mg} / \mathrm{kg} \\
\mathrm{HCQ}\end{array}$ & 64.8 & 17 & 43.7 & 85.08 & 85.4 & 5.55 & 78.51 & 92.29 & 0.0073 \\
\hline
\end{tabular}

\section{Figures}




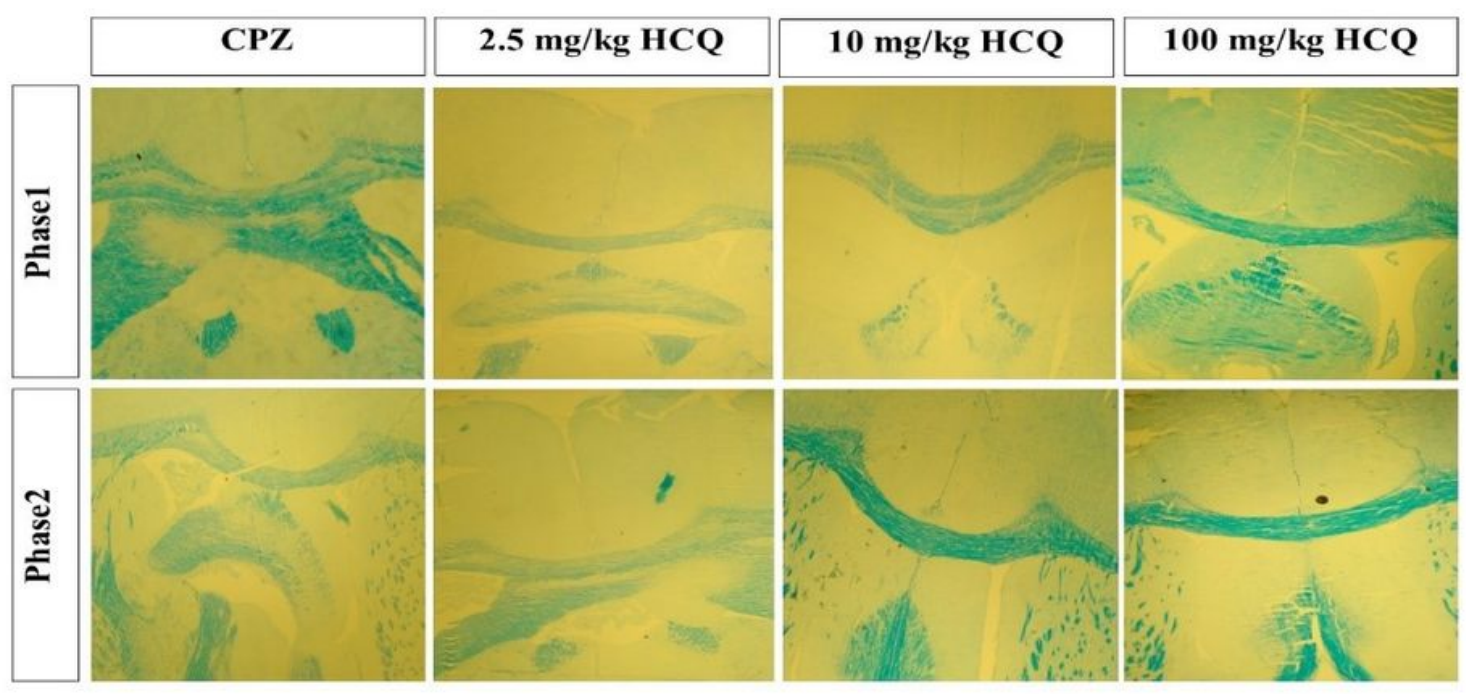

\section{Figure 1}

Microscopic images (10X) of myelin density in corpus callosum in the study groups in phase one (demyelination) and phase two (remillination). In this study, LFB staining was used to show the extent of myelin degradation in the middle region of the corpus callosum. CPZ: Cuprizone treated $(0.2 \mathrm{mg} / \mathrm{kg}$ for 5 weeks). HCQ: Hydroxycholoroquine exposure via drinking water. 
A)

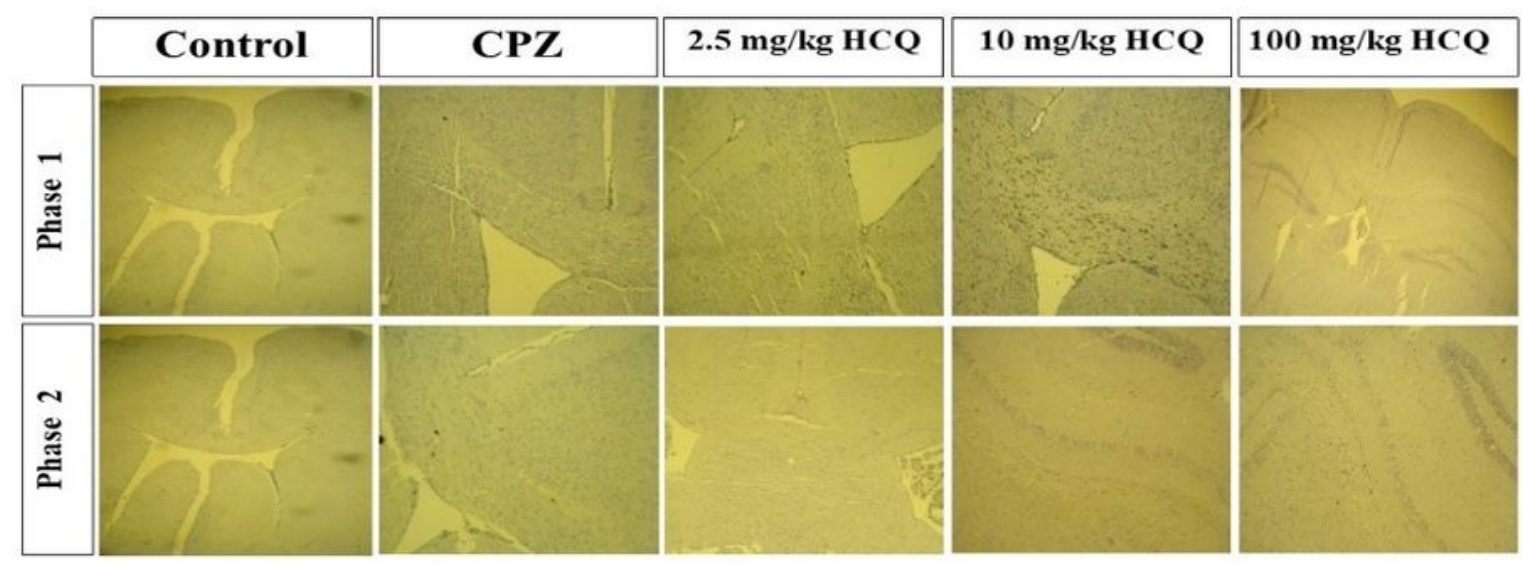

B)

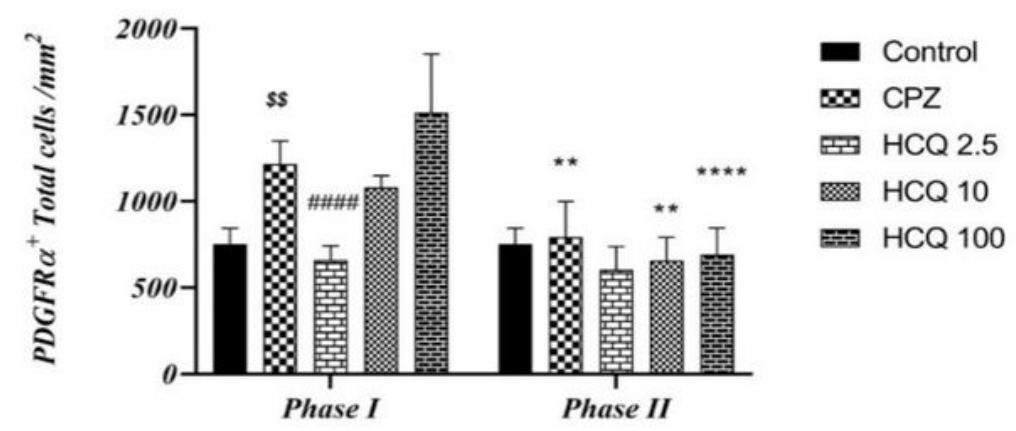

C)

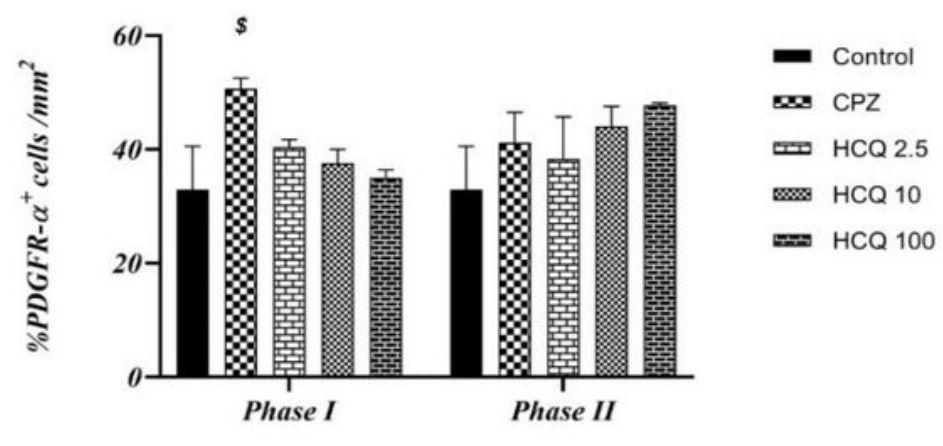

\section{Figure 2}

A) IHC staining microscopic images of PDGFR-a marker in the first phase (demylination) and the second phase (remylination) in the SVZ region with 10x magnification. B) Diagram of total cells with PDGFR-a marker in SVZ region. C) Diagram of changes in the percentage of positive cells with PDGFR-a marker in the first phases and the second phase in the SVZ region. (\#) Indicates comparison of groups with CPZ group, (\$) indicates comparison of groups with control group, $\left(^{*}\right)$ represents the comparison of similar 
groups between phases. $\left(\$ P<0.05, \$ \$ p<0.005, \$ P<0.05, * \star p<0.005,{ }^{\star \star * \star *} p<0.0001, \# \# \# \# p<0.0001, n=5-\right.$ 10).

\section{A)}

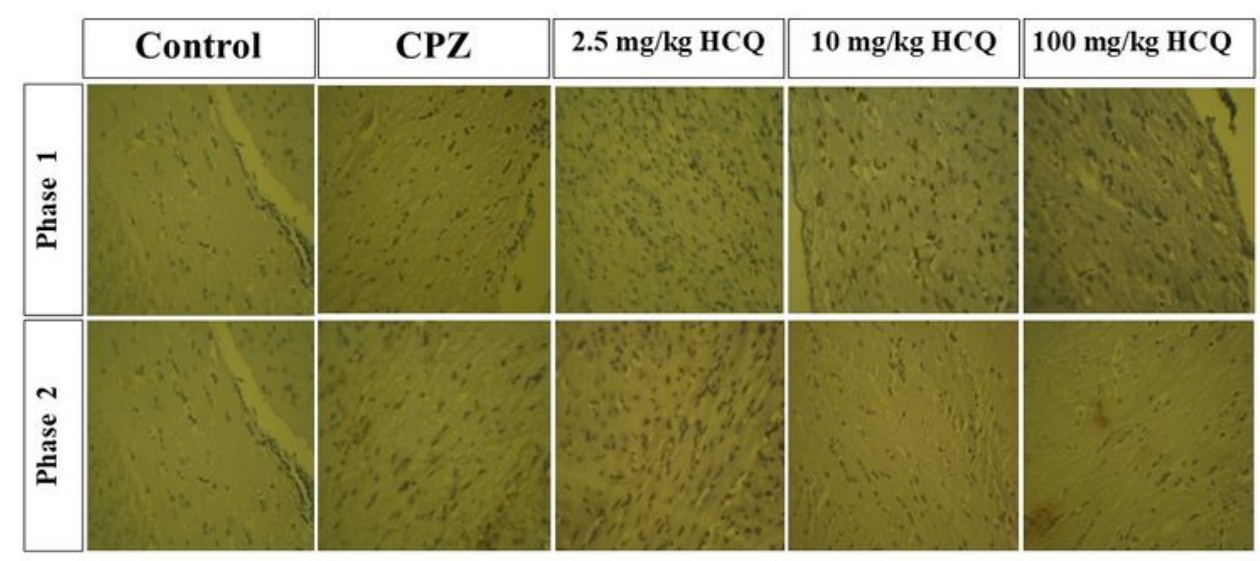

B)

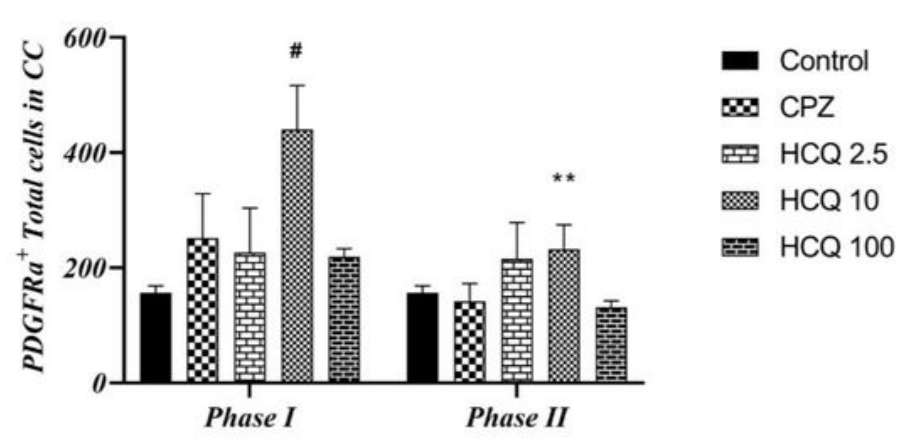

C)

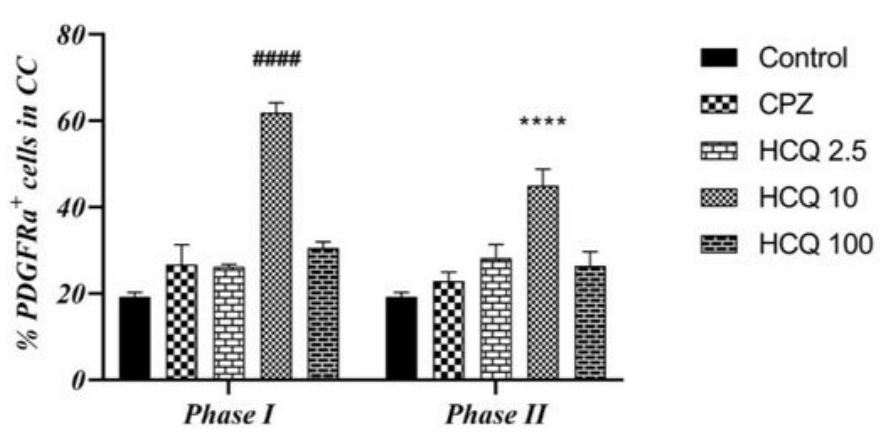

Figure 3

A) IHC staining microscopic images of PDGFR-a marker in the first phase (demylination) and the second phase (remylination) in the medial corpus callosum (CC) region with 40x magnification. B) Diagram of total cells with PDGFR-a marker in CC region. C) Diagram of changes in the percentage of positive cells 
with PDGFR-a marker in the first phases and the second phase in the CC region. (\#) Indicates comparison of groups with CPZ group, $\left(^{*}\right)$ represents the comparison of similar groups between phases. $(* \star p<0.005$, $\star \star \star \star x p<0.0001, \# p<0.05, \# \# \# \# p<0.0001, n=5-10)$.

\section{A)}

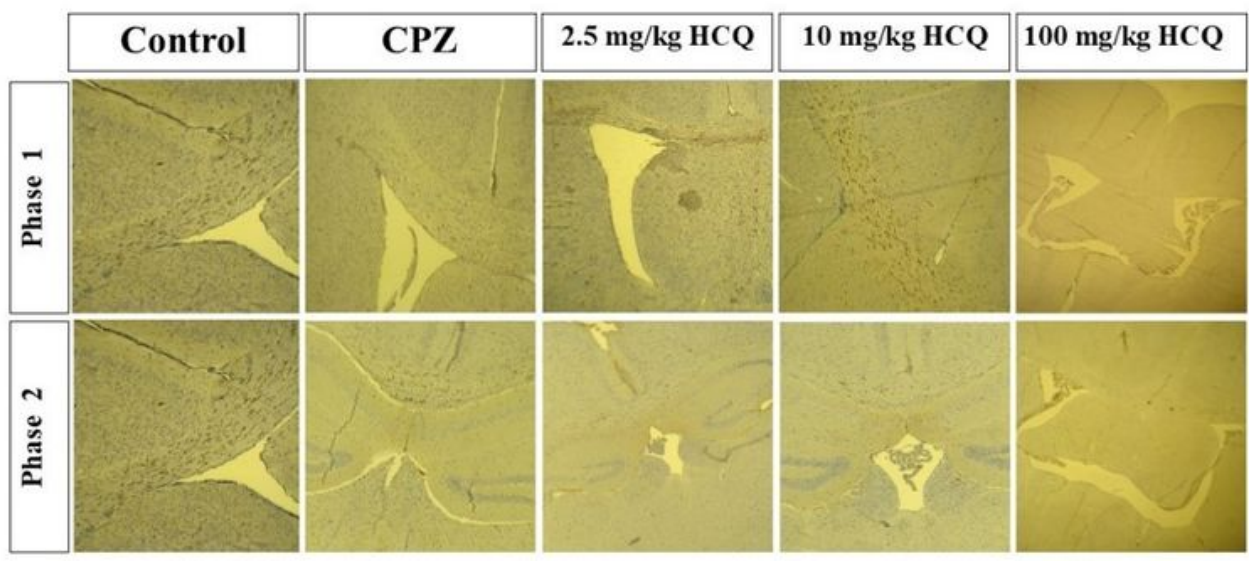

B)

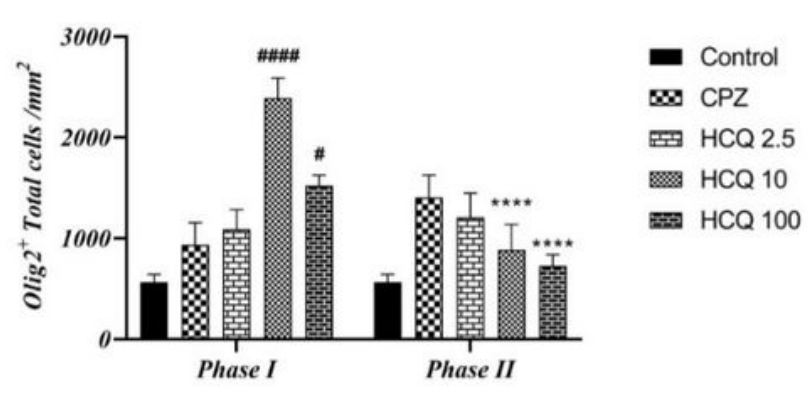

C)

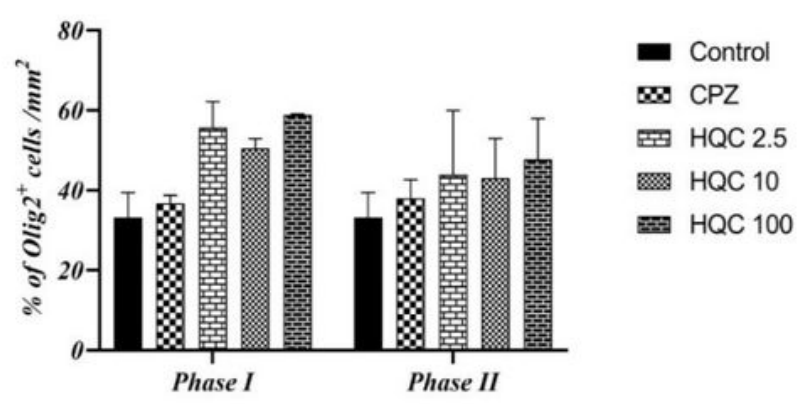

Figure 4

A) IHC staining microscopic images of olig-2 marker in the first phase (demylination) and the second phase (remylination) in the SVZ region with 10x magnification. B) Diagram of total cells with olig-2 
marker in SVZ region. C) Diagram of changes in the percentage of positive cells with olig-2 marker in the SVZ region. (\#) Indicates comparison of groups with CPZ group, (*) represents the comparison of similar groups between phases. ( $\left.{ }^{\star \star *} \mathrm{p}<0.0001, \# p<0.05, \# \# \# \# p<0.0001, \mathrm{n}=5-10\right)$.

A)

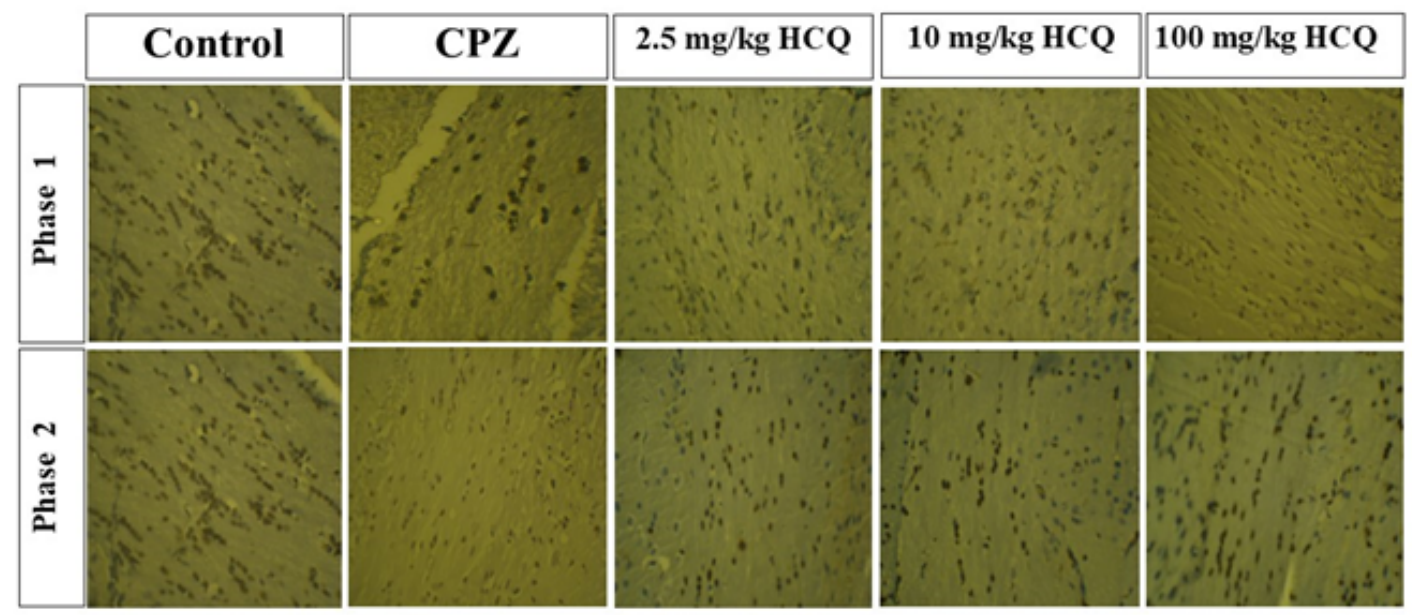

B)

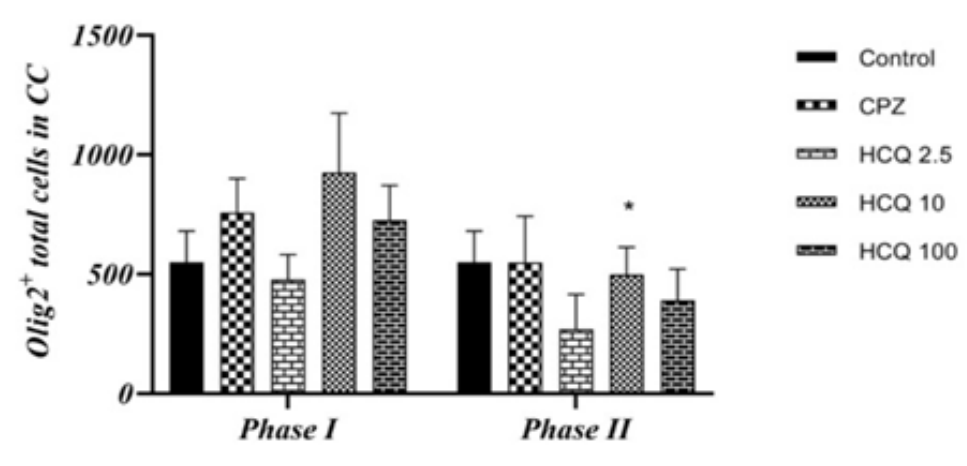

C)

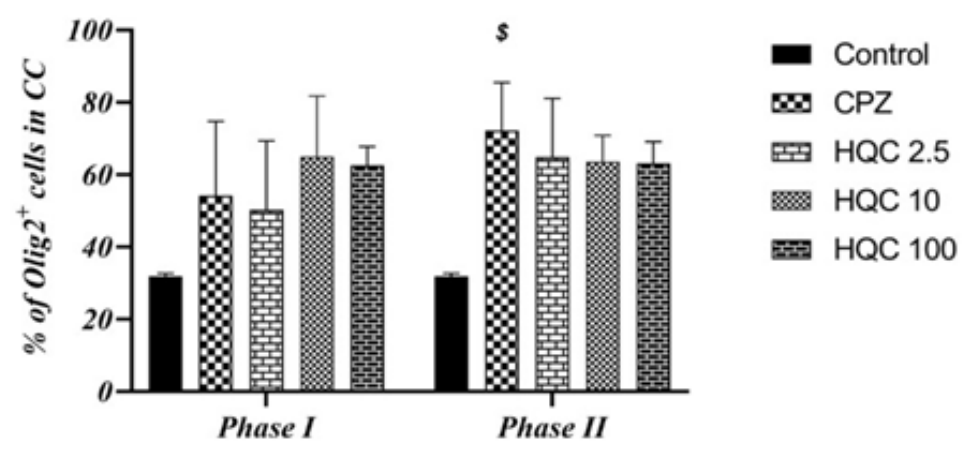

Figure 5

A) IHC staining microscopic images of olig-2 marker in the first phase (demylination) and the second phase (remylination) in the CC region with 40x magnification. B) Diagram of total cells with olig-2 marker 
in CC region. C) Diagram of changes in the percentage of positive cells with olig-2 marker in the first phase and the second phase in the CC region. (\$) Indicates comparison of groups with control group, $\left(^{*}\right)$ represents the comparison of similar groups between phases. ( $\left.{ }^{*} p<0.05, \$ p<0.05, n=5-10\right)$.

\section{Supplementary Files}

This is a list of supplementary files associated with this preprint. Click to download.

- GA.jpg 